\title{
Hour times Millimole Per Liter Per Gram
}

National Cancer Institute

\section{Source}

National Cancer Institute. Hour times Millimole Per Liter Per Gram. NCI Thesaurus. Code C106530.

Hours times millimoles per liter divided by grams. 